\title{
Fall Prevention: How To Handle a Fall ${ }^{1}$
}

IFAS EXTENSION

Leigh Ann Martin ${ }^{2}$

Follow these steps to decrease the chance of further injury after a fall.

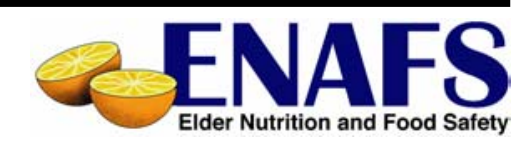

\section{Don't Panic}

After a fall, panic is often the first reaction. It's important to stay calm so you can think clearly and get help fast.

\section{Check for Injuries}

Check your body for broken bones. If you are injured, don't get up. Yell for help or crawl to the telephone and call for help.

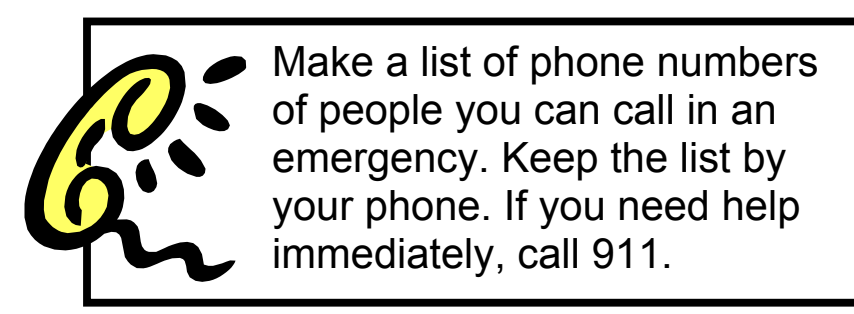

\section{Get Up if You Can}

If you can get up, do so slowly. Here's how to get up safely:

\section{Rollover onto your side}

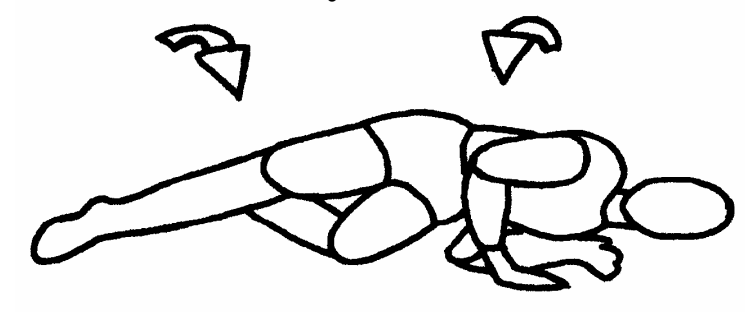

\section{Crawl to a chair}

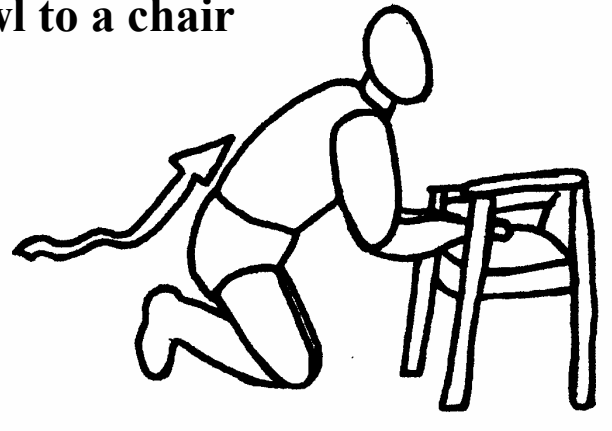

3. Pull yourself up

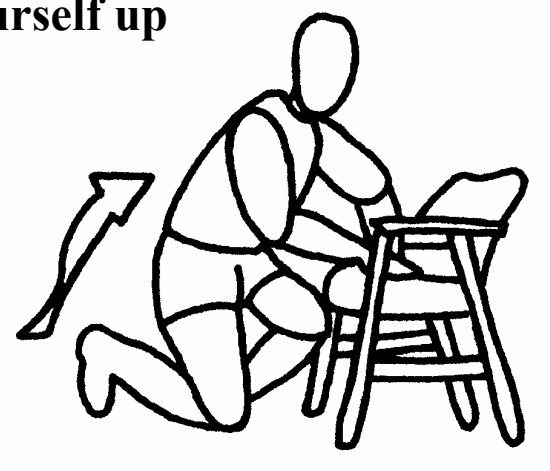

\section{Turn \& sit down}

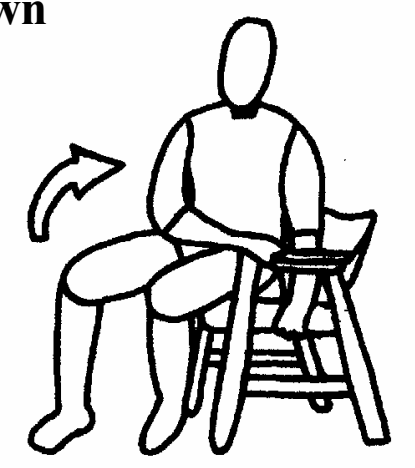

1. This document is FCS2223, one in a series of the Department of Family, Youth and Community Sciences, Florida Cooperative Extension Service, Institute of Food and Agricultural Sciences, University of Florida, Gainesville, FL 32611. Publication date: April 2005. Please visit the EDIS Website at http://edis.ifas.ufl.edu

2. Leigh Ann Martin, MS, former assistant-in, Department of Family, Youth and Community Sciences, Institute of Food and Agricultural Sciences, University of Florida, Gainesville, FL 32611. Reviewed by Linda B. Bobroff, PhD, RD, LD/N, Department of Family, Youth and Community Sciences, University of Florida. 